\title{
Why do individuals not lose more weight from an exercise intervention at a defined dose? An energy balance analysis.
}

Citation for published version (APA):

Thomas, D. M., Bouchard, C., Church, T., Slentz, C., Kraus, W. E., Redman, L. M., Martin, C. K., Silva, A. M., Vossen, M., Westerterp, K., \& Heymsfield, S. B. (2012). Why do individuals not lose more weight from an exercise intervention at a defined dose? An energy balance analysis. Obesity Reviews, 13(10), 835847. https://doi.org/10.1111/j.1467-789X.2012.01012.x

Document status and date:

Published: 01/10/2012

DOI:

10.1111/j.1467-789X.2012.01012.x

Document Version:

Publisher's PDF, also known as Version of record

Document license:

Taverne

Please check the document version of this publication:

- A submitted manuscript is the version of the article upon submission and before peer-review. There can be important differences between the submitted version and the official published version of record.

People interested in the research are advised to contact the author for the final version of the publication, or visit the DOI to the publisher's website.

- The final author version and the galley proof are versions of the publication after peer review.

- The final published version features the final layout of the paper including the volume, issue and page numbers.

Link to publication

\footnotetext{
General rights rights.

- You may freely distribute the URL identifying the publication in the public portal. please follow below link for the End User Agreement:

www.umlib.nl/taverne-license

Take down policy

If you believe that this document breaches copyright please contact us at:

repository@maastrichtuniversity.nl

providing details and we will investigate your claim.
}

Copyright and moral rights for the publications made accessible in the public portal are retained by the authors and/or other copyright owners and it is a condition of accessing publications that users recognise and abide by the legal requirements associated with these

- Users may download and print one copy of any publication from the public portal for the purpose of private study or research.

- You may not further distribute the material or use it for any profit-making activity or commercial gain

If the publication is distributed under the terms of Article $25 \mathrm{fa}$ of the Dutch Copyright Act, indicated by the "Taverne" license above, 


\title{
Etiology and Pathophysiology
}

\section{Why do individuals not lose more weight from an exercise intervention at a defined dose? An energy balance analysis}

\author{
D. M. Thomas ${ }^{1}$, C. Bouchard², T. Church², C. Slentz ${ }^{3}$, W. E. Kraus 3 , L. M. Redman², C. K. Martin², \\ A. M. Silva ${ }^{4}$, M. Vossen ${ }^{2}$, K. Westerterp ${ }^{5}$ and S. B. Heymsfield ${ }^{2}$
}

\author{
${ }^{1}$ Center for Quantitative Obesity Research, \\ Montclair State University, Montclair, NJ, USA; \\ ${ }^{2}$ Pennington Biomedical Research Center, \\ Baton Rouge, LA, USA; ${ }^{3}$ Division of \\ Cardiology, Department of Medicine, Duke \\ University Medical Center, Durham, NC, USA; \\ ${ }^{4}$ Exercise and Health Laboratory, Faculty of \\ Human Kinetics, Technical University of \\ Lisbon, Cruz-Quebrada, Portugal; \\ ${ }^{5}$ Department of Human Biology, Maastricht \\ University, Maastricht, The Netherlands
}

Received 17 November 2011; revised 9 February 2012; accepted 27 February 2012

Address for correspondence: D Thomas, Department of Mathematical Sciences,

Montclair State University, Montclair, NJ 07043, USA

E-mail: thomasdia@mail.montclair.edu

\begin{abstract}
Summary
Weight loss resulting from an exercise intervention tends to be lower than predicted. Modest weight loss can arise from an increase in energy intake, physiological reductions in resting energy expenditure, an increase in lean tissue or a decrease in non-exercise activity. Lower than expected, weight loss could also arise from weak and invalidated assumptions within predictive models. To investigate these causes, we systematically reviewed studies that monitored compliance to exercise prescriptions and measured exercise-induced change in body composition. Changed body energy stores were calculated to determine the deficit between total daily energy intake and energy expenditures. This information combined with available measurements was used to critically evaluate explanations for low exercise-induced weight loss. We conclude that the small magnitude of weight loss observed from the majority of evaluated exercise interventions is primarily due to low doses of prescribed exercise energy expenditures compounded by a concomitant increase in caloric intake.
\end{abstract}

Keywords: Body composition, compensation, energy balance, exercise.

obesity reviews (2012) 13, 835-847

\section{Introduction}

In order to lose weight, energy expenditures must exceed energy intake. To achieve this imbalance, one can decrease energy intake, increase energy expenditures or combine a decrease in intake with an increase in expenditures. As a result, most weight loss recommendations advise combining a hypo-caloric diet with an exercise component in order to achieve a significant energy deficit (1). A long-standing consistent observation is that regular exercise by itself is prescribed in small to moderate amounts resulting in modest weight loss or in some cases weight gain (2-4).

The commonly observed low levels of weight loss have led to several questions regarding the effects of regular exercise on body weight and the reasons why the energy deficit appears to be smaller than predicted. Addressing these highly debated questions (5) requires quantitative knowledge of each term in the energy balance equation:

$E S=E I-E E$

where ES represents the rate of changed body energy stores, $\mathrm{EI}$ is the rate of energy intake, and EE denotes the rate of energy expenditures typically expressed in $\mathrm{kcal} \mathrm{d}^{-1}$.

In a 1985 review, Pi-Sunyer and Woo (6) described how within an exercise study, lack of simultaneous measurements of the components of energy expenditure, body composition and EI create challenges for understanding 
physiological responses to exercise. Despite the limitations of existing studies, a number of reviews have combined the exercise literature to develop conclusions on the impact of exercise on human morphology and physiology (5-11). Here, we expand on these attempts by employing a quantitative energy balance approach to:

- ascertain the actual energy imbalance generated in each exercise intervention study retained for evaluation;

- examine the underlying reasons for the discrepancy between the actual energy imbalance and prescribed exercise expenditure;

- Improve existing body composition models that describe changes in fat-free mass (FFM) during exerciseinduced weight loss; and

- identify gaps in knowledge on the impact of regular exercise on the components of energy expenditure and the generation of substantial energy deficits.

Our calculations are based on data from carefully selected aerobic exercise studies targeting weight loss. We focus on aerobic exercise-induced weight loss because it is open to quantitative analysis and prediction in an area that has not been fully elucidated and in which uncertainties are limiting further development.

\section{Methods}

\section{Search strategy and study selection}

We performed a systematic review of the literature from 2005 to present within the PubMed database using the terms ('exercise' OR 'aerobic exercise' OR 'endurance exercise') AND ('body composition' OR 'fat mass' OR 'fat free mass') OR 'weight loss' OR 'compensation' OR 'energy balance' OR 'resting metabolic rate'. The resulting list was screened for aerobic exercise interventions within a sedentary healthy population. Aerobic exercise was defined as any activity that increased oxygen consumption, was performed at submaximal intensity, and involved large groups of skeletal muscles.

We then screened for studies that either provided total body estimates of fat mass (FM) and FFM at baseline and end of the intervention, directly measured $\mathrm{EI}$ and/or EE in confined subjects at the beginning and end of the intervention, obtained simultaneously collected doubly labelled water (DLW), FM and FFM measurements at the beginning and end of the study, or reported total energy expended from the prescribed exercise program. We additionally included relevant exercise interventions directed by the authors $(2-4,10-14)$ and studies that have been previously reviewed $(5,8,12)$.

All selected studies prescribed a dose of exercise without a reduction in diet and established compliance to the prescribed exercise dose. In all of the reviewed studies, aerobic exercise consisted of treadmill walking, treadmill running or training on cycle ergometers with interventions ranging in duration from 3 to 64 weeks $(2-4,13-25)$.

A comprehensive list of studies reviewed, the corresponding baseline characteristics of the study samples, prescribed exercise energy expenditures and methods of body composition measurement are summarized in Table 1.

The data were used to answer three questions: What is the energy deficit induced by exercise? Here we quantify the energy deficit by either calculating the change in body energy stores or the difference between EI and EE from direct measurements obtained from confined subjects. What mechanisms explain the discrepancy between the actual energy deficit and prescribed energy expenditure of the exercise program? Here we explore which terms in the energy balance equation could account for the gap between the actual energy deficit and prescribed energy expenditure of the exercise program. Specifically, these mechanisms are thought to be limited to a compensatory increase in EI, a decrease in resting metabolic rate (RMR) beyond expected at the reduced weight, or a decrease in spontaneous activity during the non-exercise hours of the day. What are the expected changes in body composition resulting from an aerobic exercise intervention and how can they influence the estimated energy deficit caused by the exercise program? Here we first identify the limitations of extrapolating the Forbes model (26-29) relating FFM and FM during changes in EI to the case of exposure to regular exercise. We then modify the model to reflect exerciseinduced body composition changes. A schematic diagram mapping the course of our analysis appears in Fig. 1.

\section{Studies that maintained El at baseline levels}

In order to segregate the effects of exercise on energy balance from any possible change in EI, EI needs to be maintained at carefully determined baseline levels. The study of Bouchard et al. (13) is unique in this regard because EI was maintained at baseline requirements and negative energy balance was generated in 14 men solely through exercise for a period of $93 \mathrm{~d}$. Subjects in the Bouchard study were confined and supervised for the entire duration of the intervention and adherence to both the exercise and dietary prescription was rigorously monitored. Additionally, RMR was measured at baseline, $50 \mathrm{~d}$, and end of study (100 d).

The study of Ross et al. $(15,16)$ was not conducted in a confined setting, although diet was monitored daily and adherence to baseline EI was confirmed through a DLW measurement midway through the study. The Ross study generated a large magnitude of energy expended through exercise comparable to reductions in intake prescribed in typical caloric restriction studies. Additionally, the Ross study included both men $(n=16)$ and women $(n=17)$. 
Table 1 Baseline characteristics, intervention length and method of measuring body composition in each of the reviewed exercise interventions

\begin{tabular}{|c|c|c|c|c|c|c|c|c|}
\hline \multirow[t]{2}{*}{ Study } & \multicolumn{4}{|c|}{ Anthropometrics } & \multirow{2}{*}{$\begin{array}{l}\text { Energy } \\
\text { imbalance } \\
\left(\mathrm{kcal} \mathrm{d}^{-1}\right)\end{array}$} & \multirow{2}{*}{$\begin{array}{l}\text { Prescribed } \\
\text { exercise } \\
\left(\mathrm{kcal} \mathrm{d}^{-1}\right)\end{array}$} & \multirow{2}{*}{$\begin{array}{l}\Delta t \\
\text { (weeks) }\end{array}$} & \multirow[t]{2}{*}{$\mathrm{BC}$} \\
\hline & Age (year) & Weight (kg) & BMI $\left(\mathrm{kg} \mathrm{m}^{-2}\right)$ & $\% F M$ & & & & \\
\hline Bouchard et al. (13) & & & & & & & 13 & uWW \\
\hline Males $(n=14)$ & 21 & 82 & 26 & 25 & -501 & -580 & & \\
\hline Ross et al. $(15,16)$ & & & & & & & 14 & MRI \\
\hline Females $(n=17)$ & 43 & 87 & 32 & 48 & -641 & -517 & & \\
\hline Males $(n=16)$ & 45 & 101 & 32 & 33 & -701 & -700 & & \\
\hline Bingham et al. (17) & & & & & & & 9 & TBK \\
\hline Females $(n=3)$ & 27 & 57 & 22 & 28 & -21 & - & & \\
\hline Males $(n=3)$ & 32 & 60 & 20 & 15 & -263 & - & & \\
\hline *Woo lean mild (18) & & & & & & & 3 & uWW \\
\hline Females $(n=5)$ & 37 & 55 & 21 & 28 & 172 & -171 & & \\
\hline *Woo lean moderate (18) & & & & & & & 3 & uWW \\
\hline Females $(n=5)$ & 37 & 55 & 21 & 28 & 30 & -429 & & \\
\hline *Woo obese mild (19) & & & & & & & 3 & uWW \\
\hline Females $(n=6)$ & 30 & 90 & 34 & 44 & -127 & -221 & & \\
\hline *Woo obese moderate (19) & & & & & & & 3 & uWW \\
\hline Females $(n=6)$ & 30 & 90 & 34 & 44 & -511 & -555 & & \\
\hline Westerterp et al. (4) & & & & & & & 44 & TC \\
\hline Females $(n=11)$ & 32 & 63 & 22 & 30 & -83 & - & & \\
\hline Males $(n=12)$ & 37 & 70 & 22 & 22 & -140 & - & & \\
\hline Sopko et al. (20) & & & & & & & 12 & $\mathrm{BD}$ \\
\hline Males $(n=4)$ & $19-44$ & 81 & - & 27 & -288 & -500 & & \\
\hline Gredigan low intensity (21) & & & & & & & 12 & uWW \\
\hline Females $(n=6)$ & 31 & 69 & 21 & 31 & -281 & -300 & & \\
\hline Gredigan high intensity (21) & & & & & & & 12 & uWW \\
\hline Females $(n=8)$ & 31 & 6,802 & 21 & 31 & -267 & -300 & & \\
\hline STRRIDE low amount moderate intensity (3) & & & & & & & 32 & SF \\
\hline Females $(n=13)$ & 57 & 76 & 29 & 39 & -44 & -151 & & \\
\hline Males $(n=11)$ & 53 & 95 & 30 & 30 & -98 & -189 & & \\
\hline STRRIDE low amount vigorous intensity (3) & & & & & & & 32 & $\mathrm{SF}$ \\
\hline Females $(n=16)$ & 57 & 76 & 29 & 37 & -80 & -153 & & \\
\hline Males $(n=22)$ & 53 & 95 & 30 & 30 & -98 & -189 & & \\
\hline STRRIDE vigorous intensity (3) & & & & & & & 32 & SF \\
\hline Females $(n=17)$ & 54 & 75 & 28 & 39 & -150 & -248 & & \\
\hline Males $(n=22)$ & 51 & 96 & 30 & 31 & -161 & -346 & & \\
\hline Goran et al. (22) & & & & & & & 8 & Siri-4 \\
\hline Females $(n=6)$ & 64 & 68 & 25 & 35 & -159 & -150 & & \\
\hline Males $(n=5)$ & 69 & 74 & 24 & 26 & -114 & -150 & & \\
\hline INFLAME (2) & & & & & & & 16 & DXA \\
\hline Females $(n=52)$ & 51 & 82 & 31 & 43 & -64 & -215 & & \\
\hline Males $(n=14)$ & 51 & 93 & 29 & 32 & -39 & -215 & & \\
\hline Després et al. (23) & & & & & & & 56 & uWW \\
\hline Females $(n=13)$ & 39 & 90 & 35 & 47 & -102 & -350 & & \\
\hline DREW low dose (14) & & & & & & & 24 & SF \\
\hline Females $(n=131)$ & 58 & 86 & 31 & 32 & -44 & -48 & & \\
\hline DREW moderate dose (14) & & & & & & & 24 & SF \\
\hline Females $(n=85)$ & 57 & 83 & 32 & 35 & -37 & -91 & & \\
\hline DREW high dose (14) & & & & & & & 24 & SF \\
\hline Females $(n=93)$ & 56 & 83 & 31 & 35 & -14 & -123 & & \\
\hline Donnelly et al. (25) & & & & & & & 64 & uWW \\
\hline Females $(n=25)$ & 24 & 77 & 29 & 36 & -2 & -286 & & \\
\hline Males $(n=16)$ & 22 & 94 & 30 & 29 & -104 & -286 & & \\
\hline
\end{tabular}

${ }^{*}$ Intervention was separated into three phases each lasting a period of $19 \mathrm{~d}$; sedentary, mild dose of exercise and moderate dose of exercise. Magnitude of energy imbalance resulting from each intervention calculated from mean changed body energy stores: $1,020 \frac{\Delta F F M}{\Delta t}+9,500 \frac{\Delta F M}{\Delta t}$. If prescribed energy expenditures from exercise were not directly reported, we determined this amount by multiplying the reported exercise intensity by the duration of each session. We then averaged the amount over the length of the intervention to arrive at a prescribed energy expended through exercise. The total oxygen consumed during exercise was converted to energy cost by multiplying each litre of $\mathrm{VO}_{2}$ by $5 \mathrm{kcal}$. Duration of the trial represented by $\Delta t$ and $\mathrm{BC}$-labelled column denotes body composition method (BD, body density; DXA, dual energy x-ray absorptiometry; MRI, magnetic resonance imaging; SF, skin-fold; Siri-4, Siri-four compartment model; TBK, total body K; TC, three-compartment model based on body weight, body volume, body density; UWW, underwater weighing).

BC, body composition; BMI, body mass index; DREW, Dose-Response to Exercise in postmenopausal Women study; FM, fat mass; INFLAME, Inflammation and Exercise study; STRRIDE, Studies of Targeted Risk Reduction Interventions Through Defined Exercise. 


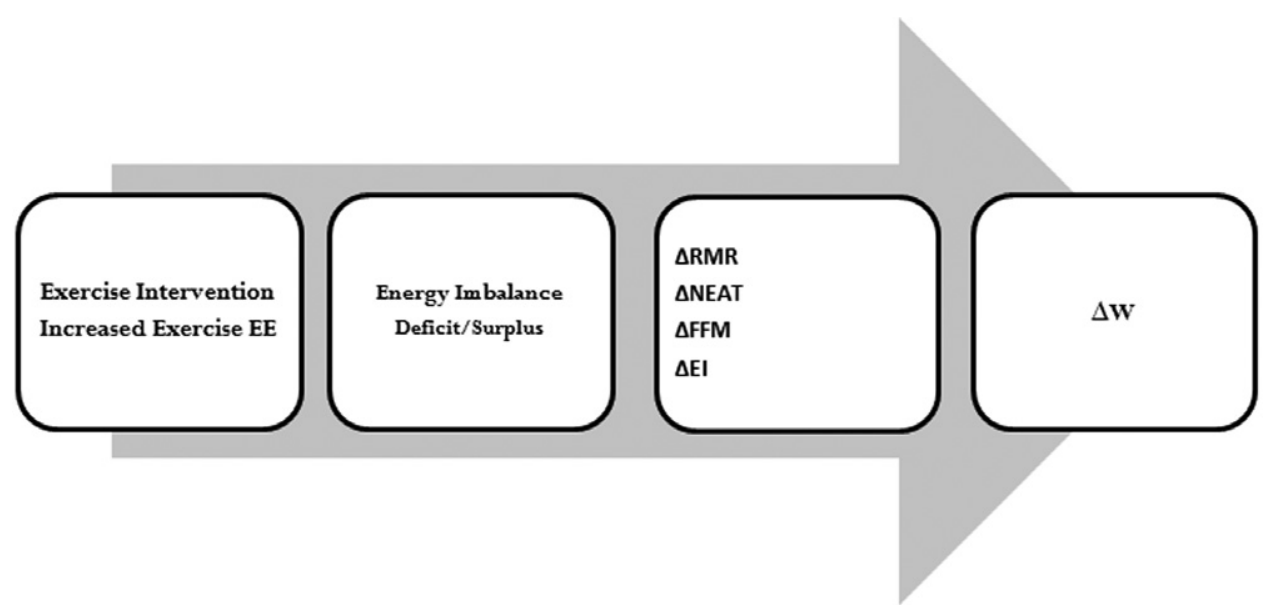

Figure 1 Diagram that maps the progression of study analysis begins with the exercise intervention which increases exercise energy expenditure. The increase will lead to an energy imbalance which may translate to an energy deficit or an energy surplus. The mechanistic influences on energy imbalance that are examined are changes to resting metabolic rate (RMR), non-exercise activity (NEAT), fat-free mass (FFM) and energy intake (EI). The impact of these changes on energy imbalance translates to changed body weight (W).

\section{Studies that confined and supervised ad libitum El and EE}

Studies (17-19) were conducted in a confined setting and although EI was not maintained at baseline levels, EI and EE were both directly measured. Both men $(n=3)$ and women $(n=14)$ were included in these studies with subjects body mass index (BMI) ranging widely (19.5$34.3 \mathrm{~kg} \mathrm{~m}^{-2}$ ).

\section{Studies that obtained doubly labelled water-measured EE}

The study of Westerterp et al. (4) obtained DLW measurements of total energy expenditures at baseline and end of study in 13 of the 23 subjects.

\section{Studies of free-living subjects}

The studies $(2-4,14,20-25)$ were conducted in free-living subjects. Although subjects in most of the studies were asked to maintain baseline EI, dietary adherence was not objectively measured. These studies are particularly important as they can be compared to results from confined studies to understand how subject measurements potentially deviate from controlled conditions.

\section{Calculation of energy imbalance}

The average energy imbalance can be calculated from the average rate of change in body energy stores from the beginning to the end of the study, ES in Equation 1. If $E S$ is negative (negative energy balance), then $E E$ is larger in magnitude than EI. Likewise, if EI is positive (positive energy balance), then EE is smaller in magnitude than EI. Using the established energy densities (30) of $1,020 \mathrm{kcal} \mathrm{kg}^{-1}$ for FFM and 9,500 kcal kg-1 for FM, we applied Formula 2 to quantify the average rate of changed body energy stored or lost in $\mathrm{kcal} \mathrm{d}^{-1}$ :

$$
E S=1,020 \frac{\Delta F F M}{\Delta t}+9,500 \frac{\Delta F M}{\Delta t}
$$

where $\triangle F F M$ and $\triangle F M$ represent the change in $\mathrm{kg}$ of FFM and FM from beginning to end of the intervention and $\Delta t$ is the time length of the trial in days. Determining energy imbalance from the change in body energy stores (Equation 2) has recently been validated experimentally in several studies $(31,32)$.

\section{Determination of prescribed exercise energy expenditures}

If prescribed energy expenditures were not directly reported, we determined the exercise prescription level in $\mathrm{kcal} \mathrm{d}^{-1}$ by multiplying the reported exercise intensity by the duration of each session. We then averaged the amount over the length of the intervention to arrive at a prescribed energy expended through exercise.

\section{Calculation of the magnitude of compensation}

The existing formal definition for degree of compensation during aerobic exercise is the difference in expected weight and actual weight (14). This definition relies on the accuracy of the applied model. We revised the definition of compensation as the magnitude of difference between achieved energy imbalance and prescribed expenditures.

\section{Expected post-intervention resting metabolic rate}

The per cent metabolic adaptation is defined as the per cent decrease in RMR beyond expected at the reduced weight 
$(33,34)$. Metabolic adaptation has been observed during periods of caloric restriction $(33,34)$. To determine whether metabolic adaptation occurs in response to an exercise program, we require longitudinal RMR data in subjects who maintained baseline EI and achieved a negative energy balance solely through exercise. Therefore, we restricted our analysis of exercise-induced changes in RMR to the study of Bouchard et al. (13), which was the only confined experiment that generated a negative energy balance from exercise and included longitudinal measurements of RMR. Calculation of metabolic adaptation followed previously published methods $(33,34)$.

First, RMR was regressed against FFM at baseline to generate linear equations that were then used to calculate expected values of RMR at $100 \mathrm{~d}$ from observed values of FFM (denoted $R M R_{e}$ ). Differences between expected and observed RMR were analyzed at $100 \mathrm{~d}$ through a BlandAltman analysis (35). Per cent metabolic adaptation was calculated as the average of the individual per cent metabolic adaptation:

$1-\frac{R M R_{a}}{R M R_{e}}$

where $R M R_{a}$ represents actual observed post-intervention RMR.

\section{Calculation of energy intake}

When DLW-measured EE is obtained in conjunction with measured body composition, then two terms of the energy balance equation are known, namely ES and EE. From here, we solved for average EI during the course of the intervention:

$E I=E S+E E=1,020 \frac{\Delta F F M}{\Delta t}+9,500 \frac{\Delta F M}{\Delta t}+E E$

\section{Development of fat-free mass-fat mass relationship during aerobic exercise}

Bland-Altman analysis of Forbes curve predictions

The Forbes curve (26)

$F F M=10.4 \ln \left(\frac{F M}{C}\right)$

where the parameter, $C$, is a function of baseline body composition,

$C=\frac{F M_{0}}{e^{\left(\frac{F F M_{0}}{10.4}\right)}}$

defines a relationship between FFM and FM, and has been successfully applied within differential equation models that predict weight change resulting from changes in EI (36-38). We remark that the curve originally defined by Forbes (26) did not include the parameter, C. The inclusion of the parameter, C, combines the effect of gender, age and race on baseline body composition in a single parameter (36). Although folding these covariates into a single parameter is not optimal, the resulting equation is technically simple to apply within a more complex dynamic model and in the case of caloric restriction provides a comparable degree of accuracy predicting $\triangle F F M(39)$.

In order to determine the quality of Forbes curve predictions during an exercise program, we conducted a BlandAltman analysis comparing Forbes curve-predicted change in FFM $(\triangle \mathrm{FFM})$ to observed $\triangle \mathrm{FFM}$ in a study where negative energy balance was induced solely through caloric restriction (40), a combination of caloric restriction and exercise (40), and solely through exercise (13). We determined whether the level of agreement between Forbes curve predictions and observed data altered with the inclusion of exercise. The statistical analysis was conducted using $\mathrm{R}$ 2.11.0 (GNU, 2011).

For the Bland-Altman analysis, we applied data from subjects who achieved weight loss solely through caloric restriction and caloric restriction combined with exercise from a reference database of the 24-week Comprehensive Assessment of Long-term Effects of Reducing Intake of Energy (CALERIE) Study conducted at the Pennington Biomedical Research Center (40). This study was selected because dietary adherence was monitored through multiple simultaneous measurements of ES and EE (32). For the case of weight loss achieved solely through caloric restriction, we limited our analysis to the 12 CALERIE subjects that were placed on a continuous $25 \%$ calorie-restricted diet for a period of 24 weeks. The combined diet and exercise database was also taken from the CALERIE study where we limited our analysis to the 12 subjects prescribed a combination of continuous caloric restriction $(12.5 \%$ calorie restriction) and exercise, which increased energy expenditure by $12.5 \%$. Finally, we analyzed the degree of agreement between Forbes predicted vs. observed $\triangle \mathrm{FFM}$ in the Bouchard study (13).

The Bland-Altman analysis revealed the magnitude of observed $\triangle \mathrm{FFM}$ in response to aerobic exercise will be less than predicted by the Forbes curve. Thus, we fit a piecewise-modified Forbes curve for the case where FM decreases below baseline levels $\left(F M_{0}\right)$ and the case where FM increases above $F M_{0}$.

The mathematical representation of these cases can be expressed as

$$
F F M=\left\{\begin{array}{l}
a_{1} \ln \left(\frac{F M}{C}\right) \text { if } F M<F M_{0}, \\
a_{2} \ln \left(\frac{F M}{C}\right) \text { if } F M>F M_{0}
\end{array}\right.
$$


To determine the parameter $a_{1}$ we applied the study by Ross et al. $(15,16)$ where subjects achieved a negative energy balance equivalent to the prescribed increase in physical activity. The other branch of the modified Forbes curve required knowledge of changes in body composition for a cohort who increased intake while on an aerobic exercise intervention. To fit the parameter $a_{2}$ we applied data from the Inflammation and Exercise study (INFLAME) (2). Forty-two per cent of the INFLAME subjects $(\mathrm{N}=28 / 66)$ increased FM. Additionally, 99.9\% compliance to exercise protocols was established.

The newly developed model was validated on the data from the study of Bouchard et al. (13).

\section{Results}

Estimated mean energy imbalance for each reviewed study was calculated using Equation 2 and the results are reported in Table 1.

\section{Energy imbalance validity}

We compared the amount of energy imbalance achieved calculated from changed body energy stores (Equation 2) with the directly measured energy deficit in confined studies $(13,18,19)$. Estimated mean energy imbalance agreed with directly measured negative energy balance within $80 \mathrm{kcal} \mathrm{d}^{-1}$ in the Bouchard study (13), within $145.1 \mathrm{kcal} \mathrm{d}^{-1}$ for the Woo Lean study (18) and within $141.7 \mathrm{kcal} \mathrm{d}^{-1}$ in the Woo Obese study (19).

Next we compared conclusions obtained from calculated energy imbalance to study conclusions arrived from alternative methods. The Dose-Response to Exercise in postmenopausal Women study (DREW) compared actual weight loss to expected weight loss using the rule that a $3,500 \mathrm{kcal}$ deficit yields a lb of weight loss (14). The DREW analysis determined that subjects completing a higher dose of exercise achieved significantly less weight loss than expected compared to the subjects completing lower exercise doses. Hence, under the former definition of compensation (14), subjects who conducted higher doses of exercise compensated more than subjects who completed lower doses. Similarly, under our modified definition of compensation, the high-dose exercisers compensated more than the low-dose exercisers.

The Woo Lean and Woo Obese studies $(18,19)$ concluded lean subjects increased their intake to remain in energy balance while the obese did not. This observation was supported by our energy imbalance calculation which demonstrated that energy imbalance for the lean subjects was close to zero while the energy imbalance for obese subjects agreed closely with prescribed energy expenditures from exercise.

\section{Studies where the magnitude of energy imbalance agrees with the prescribed energy expended through exercise}

The mean reported energy expended from exercise in the Bouchard study (13) was $-580 \mathrm{kcal} \mathrm{d}^{-1}$. When compared to the mean- achieved energy imbalance calculated from Equation 2 we arrived at $-500 \mathrm{kcal} \mathrm{d}^{-1}$. Similarly, meanachieved energy imbalance $\left(-701 \mathrm{kcal} \mathrm{d}^{-1}\right)$ closely agreed with amount of prescribed exercise energy expenditures $\left(-700 \mathrm{kcal} \mathrm{d}^{-1}\right)$ in male subjects of the Ross study where dietary adherence was monitored daily $(15,16)$. We also found that for the Woo Obese study (19), calculated mean energy imbalance was $-511 \mathrm{kcal} \mathrm{d}^{-1}$, which closely agreed with the prescribed energy expended from exercise $\left(-555 \mathrm{kcal} \mathrm{d}^{-1}\right)$.

\section{Studies where achieved energy imbalance does not agree with prescribed energy expended from exercise}

From Table 1 we observe that for the majority of studies, the magnitude of achieved energy imbalance was consistently lower than prescribed energy expenditure from exercise. Because the additional energy expenditures through physical activity were rigorously supervised, the low magnitude of energy imbalance must have been a result of metabolic adaptation, decreased non-exercise activity or a compensatory increase in EI. We explored evidence for each possible response.

\section{Evidence for metabolic adaptation}

Several reviews have examined the effect of aerobic exercise interventions in sedentary populations on RMR (7,911). Several studies report increases in RMR while some report no change (7-11). However, from Table 1 we observe that the energy imbalance in the majority of studies is very low, and therefore the observed response in RMR may have resulted from an insufficient magnitude of negative energy balance. Hence, based on the previous literature, we could not conclusively determine that RMR is unchanged or increased as a result of an aerobic exercise intervention. As reported in a recent review (10), we can only conclude that RMR does not change as long as body weight is maintained. Thus, the question remains whether adaptations would exist if EI was maintained at baseline levels.

In the Bouchard experiment (13), where EI was maintained at baseline levels, FFM accounted for $67 \%$ of the variance in $\mathrm{RMR}\left(\mathrm{RMR}=17.3 \mathrm{FFM}+156.4, \mathrm{R}^{2}=0.67\right.$, $P<0.0004)$, where RMR is expressed in $\mathrm{kcal} \mathrm{d}^{-1}$ and FFM in kg. The top panel of Fig. 2 illustrates that the observed 
(a)

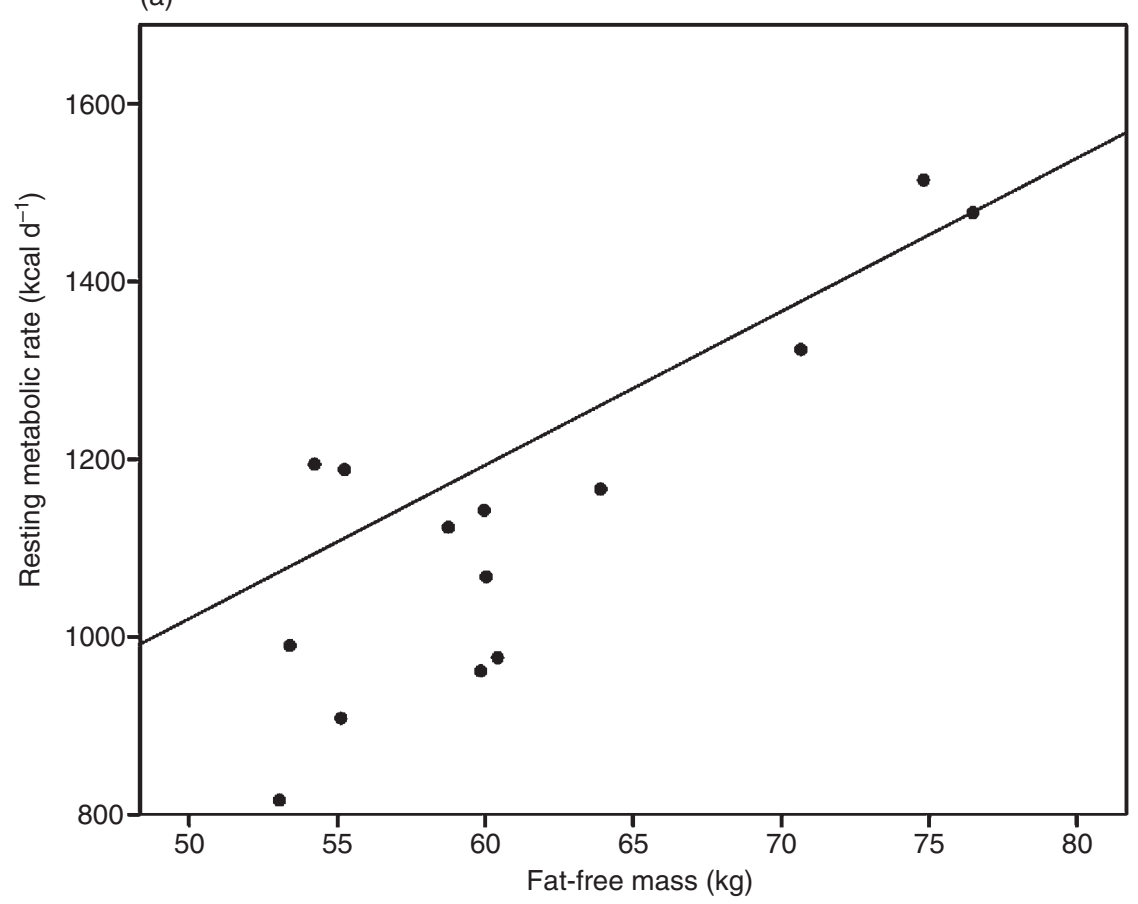

(b)

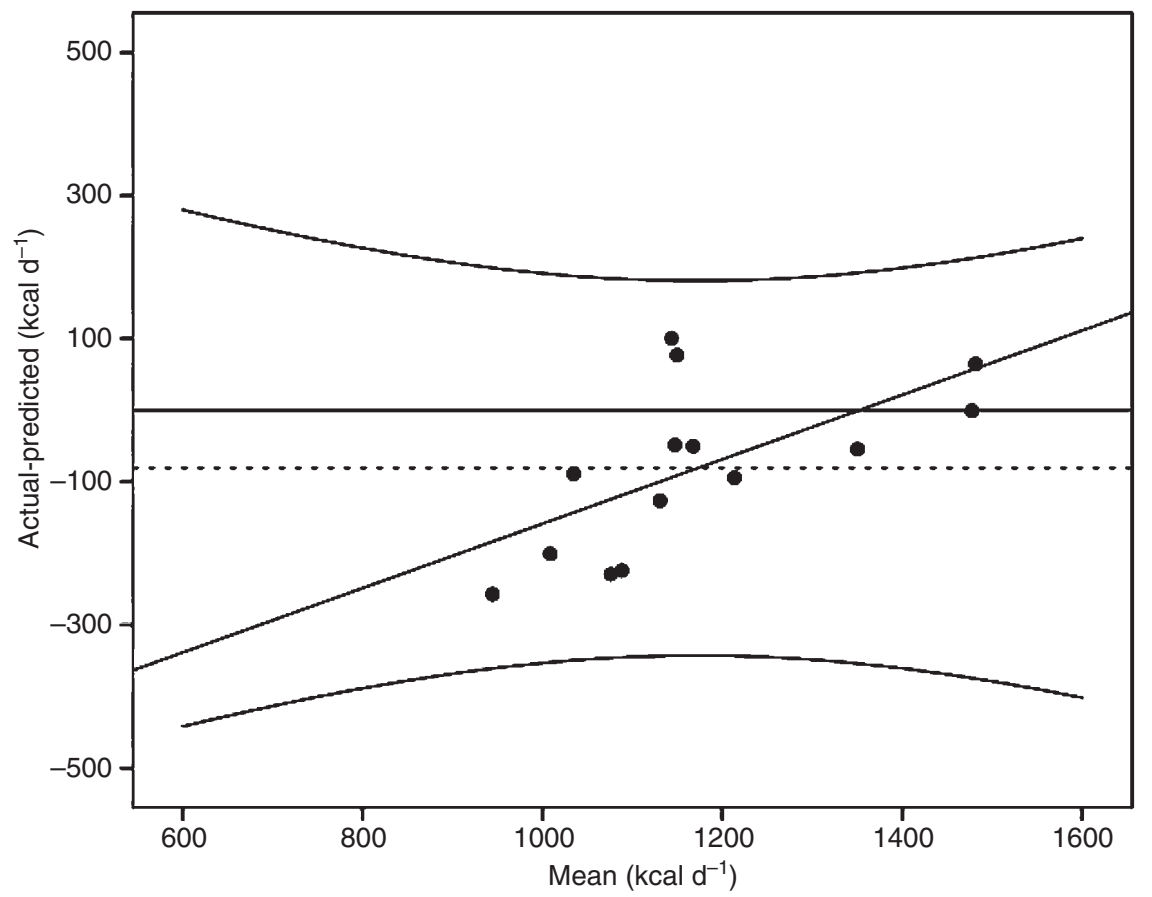

Figure 2 Top panel: Linear regression at baseline between resting metabolic rate (RMR) and fat-free mass (FFM; $\mathrm{kg})(\mathrm{RMR}=17.3 \mathrm{FFM}+156.4$, $R^{2}=0.66$ ) and observed RMR values (closed circles) post intervention in the study of Bouchard et al. (13). The observed values falling below the regression line, particularly at lower levels of FFM, indicate metabolic adaptation. Bottom panel: Bland-Altman plot comparing expected vs. post-intervention-observed RMR. The Bland-Altman analysis revealed a bias of $-80.9 \mathrm{kcal} \mathrm{d}^{-1}$ with $95 \%$ confidence intervals of -311 and 149 , although this bias was not consistent over levels of RMR (slope $=0.45$ intercept $=-608.6, R^{2}=0.39$ ), indicating that metabolic adaptation primarily occurs for individuals with lower RMRs or body mass. 
RMR values at $100 \mathrm{~d}$ are lower than the RMR values that were predicted based on FFM (i.e. the observed RMR values or closed circles are below the regression line), although this discrepancy is largest for individuals who had lower levels of FFM. This is confirmed with the BlandAltman analysis that revealed a mean bias of $-81 \mathrm{kcal} \mathrm{d}^{-1}$ (95\% confidence intervals: $[-148,-13]$; one-sample $t$-test $t=-2.58, P<0.05)$ or $7 \%( \pm 1 \%$ standard deviation $)$, suggesting the existence of exercise-induced metabolic adaptation when baseline EI is maintained (Fig. 2, bottom panel). Further, the Bland-Altman analysis revealed that metabolic adaptation is most pronounced at the lower levels of RMR $\left(y=0.5 x-608.53, \mathrm{R}^{2}=0.386\right)$, which supports the observations from the regression in the top panel of Fig. 2.

\section{Evidence for a decrease in non-exercise activity}

The review (12) found that in the case where body weight is maintained, activity external to prescribed physical activity did not decrease except in elderly subjects. Recent use of accelerometers confirms that no noticeable differences in physical activities not associated with the exercise intervention can be detected (4). In existing studies that collected accelerometer data, there is little change in body weight and lack of objectively measured dietary intake precludes extrapolation to a case when large negative energy balance is induced from exercise. To our knowledge, there does not exist a study that measured non-exercise movements when EI was maintained at baseline levels. The only evidence that non-exercise activity is not a major contributor to low weight loss is that the energy imbalance determined from the studies of Bouchard et al. and Ross et al. $(13,15,16)$ does not significantly differ from prescribed increased exercise expenditures.

\section{Evidence for dietary compensation}

Because of the previously mentioned difficulty in measuring the different contributors to the terms in the energy balance equation during an exercise intervention, one cannot simply use the low magnitude of imbalance calculated from changed body energy stores and conclude the presence of a compensatory increase in dietary intake. Errors in selfreported intake prevent the use of dietary records as a reliable measure of changes in intake during an exercise intervention (41). Thus, we must restrict our analysis to studies that measured both changed body composition and energy expenditures by DLW (4).

Twelve of 13 individuals from which changed body composition and DLW-assessed energy expenditures were obtained in the study of Westerterp et al. (4) increased intake during the respective intervention. Additionally, Woo et al. (18) found that five lean women increased intake to match their increased energy expenditures during the intervention, but did not observe the same result for the six obese women (19).

\section{Does exercise preserve lean tissue?}

Fourteen of the 15 aerobic exercise intervention studies resulted in very little change in FFM despite changes in FM. From this, it may be tempting to conclude that aerobic exercise preserves lean tissue; however, as stated previously, EI in the majority of these studies was unknown. Thus, the observed preservation of FFM may be a result of increased EI.

Forbes observed FFM loss during aerobic exercise and hypothesized that the response is similar to those observed in caloric restriction interventions (27-29). Loss of FFM was similarly observed in 51\% (34/66) individual subjects in the INFLAME study (2). However, the large magnitude of achieved energy imbalance in the Bouchard and Ross studies $(13,15,16)$, resulted in no significant change in FFM. Thus, the question remains to what degree FFM will decrease in response to exercise. It has been suggested that the Forbes curve predicts changes in FFM during exercise (29,36-38) and we begin by examining this hypothesis.

\section{The Forbes curve}

The original Forbes curve is well established as a model describing changes in FFM during caloric restriction (26,36-38). This observation is reconfirmed by our BlandAltman analysis from the Forbes curve predictions of the change in FFM resulting solely from caloric restriction in the CALERIE Phase I study (40). In this case, the BlandAltman analysis (first row of Fig. 3) indicates good agreement between Forbes curve predictions of change in FFM and actual change in FFM (Pearson correlation coefficient, $\mathrm{R}=0.70, P=0.02)$ with a low bias of $0.26 \mathrm{~kg}(95 \%$ limits of agreement $-1.80,2.34 \mathrm{~kg}$ ).

However, with the introduction of aerobic exercise, agreement of the predicted changes in FFM by the Forbes curve weakens (second row of Fig. 3). Our Bland-Altman analysis revealed an increased bias $(1.16 \mathrm{~kg}, 95 \%$ limits of agreement $-2.02,4.35 \mathrm{~kg}$ ) with caloric restriction combined with exercise and the correlation between predicted change in FFM and actual change in FFM is not significant $(\mathrm{R}=0.35, P=0.30)$. This bias increases further (third row of Fig. 3 , bias $=3.63 \mathrm{~kg}, 95 \%$ limits of agreement -0.52 , $7.78 \mathrm{~kg}$ ) in the case of negative energy balance achieved solely through aerobic exercise, with a weaker correlation that is again not significant $(\mathrm{R}=-0.06, P=0.72)$.

Our analysis reveals that the Forbes curve overestimates the decrease in FFM during aerobic exercise. As a result, we modified the Forbes curve to account for the smaller observed decrease. 

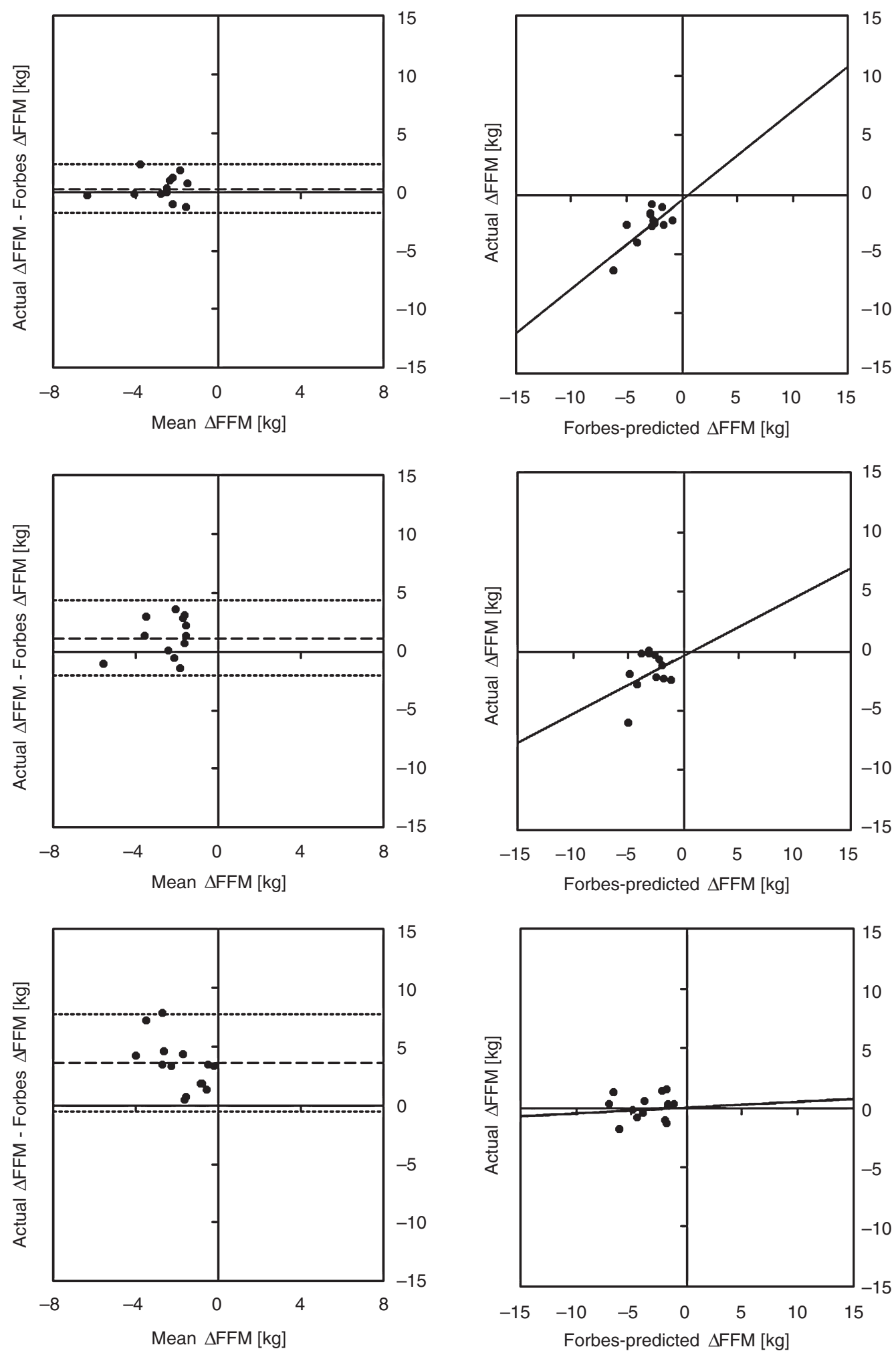

Figure 3 The Forbes curve does not predict $\triangle F F M$ during aerobic exercise. Bland-Altman plots depicting Forbes curve predictions of $\Delta F F M(\mathrm{~kg})$ for caloric restriction alone from Comprehensive Assessment of Long-term Effects of Reducing Intake of Energy (CALERIE) Phase I (40) (first row), caloric restriction combined with aerobic exercise from CALERIE Phase I (40) (second row) and aerobic exercise alone from the Bouchard trial (13) (third row). The Bland-Altman indicates good agreement for caloric restriction alone $\left(R^{2}=0.52, P=0.02\right.$ [significant correlation] with a low bias $[0.3 \mathrm{~kg}])$. The bias increases for caloric restriction combined with exercise $(1.2 \mathrm{~kg})$ and the correlation is not significant $\left(\mathrm{R}^{2}=0.13, P=0.30\right)$. The bias increases further for aerobic exercise alone $(3.6 \mathrm{~kg})$ and the correlation is once again not significant $\left(R^{2}=0.01, P=0.727\right)$. FFM, fat-free mass. 
Table 2 Modified Forbes model predictions vs. observed changes in fat-free mass

\begin{tabular}{|c|c|c|c|c|c|c|c|c|}
\hline Gender & $\begin{array}{l}\text { Baseline } \\
\text { FM (kg) }\end{array}$ & $\begin{array}{l}\text { Baseline } \\
\text { FFM (kg) }\end{array}$ & $\begin{array}{l}\text { Final } \\
\text { FM } \\
(\mathrm{kg})\end{array}$ & $\begin{array}{l}\text { Final } \\
\text { FFM } \\
(\mathrm{kg})\end{array}$ & $\begin{array}{l}\text { Forbes-predicted } \\
\text { final FFM }(\mathrm{kg})\end{array}$ & $\begin{array}{l}\text { Forbes } \\
\text { error (kg) }\end{array}$ & $\begin{array}{l}\text { Modified } \\
\text { Forbes-predicted } \\
\text { FFM }(\mathrm{kg})\end{array}$ & $\begin{array}{l}\text { Modified } \\
\text { Forbes } \\
\text { error }(\mathrm{kg})\end{array}$ \\
\hline \multicolumn{9}{|c|}{ Ross et al. $(15,16)$} \\
\hline M & 33.1 & 67.9 & 27 & 67 & 65.78156 & -1.2 & 66.7 & -0.3 \\
\hline $\mathrm{F}$ & 41.2 & 45.6 & 34.5 & 46.4 & 43.75422 & -2.6 & 44.5 & -1.9 \\
\hline \multicolumn{9}{|c|}{ INFLAME (2) } \\
\hline M & 33.9 & 68.2 & 34.7 & 69.3 & 68.5 & -0.9 & 68.5 & -0.8 \\
\hline $\mathrm{F}$ & 34.9 & 47.1 & 36.1 & 46.9 & 47.4 & 0.5 & 47.5 & 0.6 \\
\hline \multicolumn{9}{|c|}{ Bouchard et al. (13) } \\
\hline M & 20.8 & 61.2 & 15.9 & 61.1 & 58.4 & -2.7 & 59.6 & 0.3 \\
\hline
\end{tabular}

Actual FFM (kg), Forbes and modified Forbes-predicted FFM (kg) with calculated error (kg) (difference between actual and predicted) in the Ross $(15,16)$ and INFLAME (2) studies on which the modified model was developed. The model was validated on the Bouchard data set $(13)$.

FFM, fat-free mass; FM, fat mass; INFLAME, Inflammation and Exercise study.

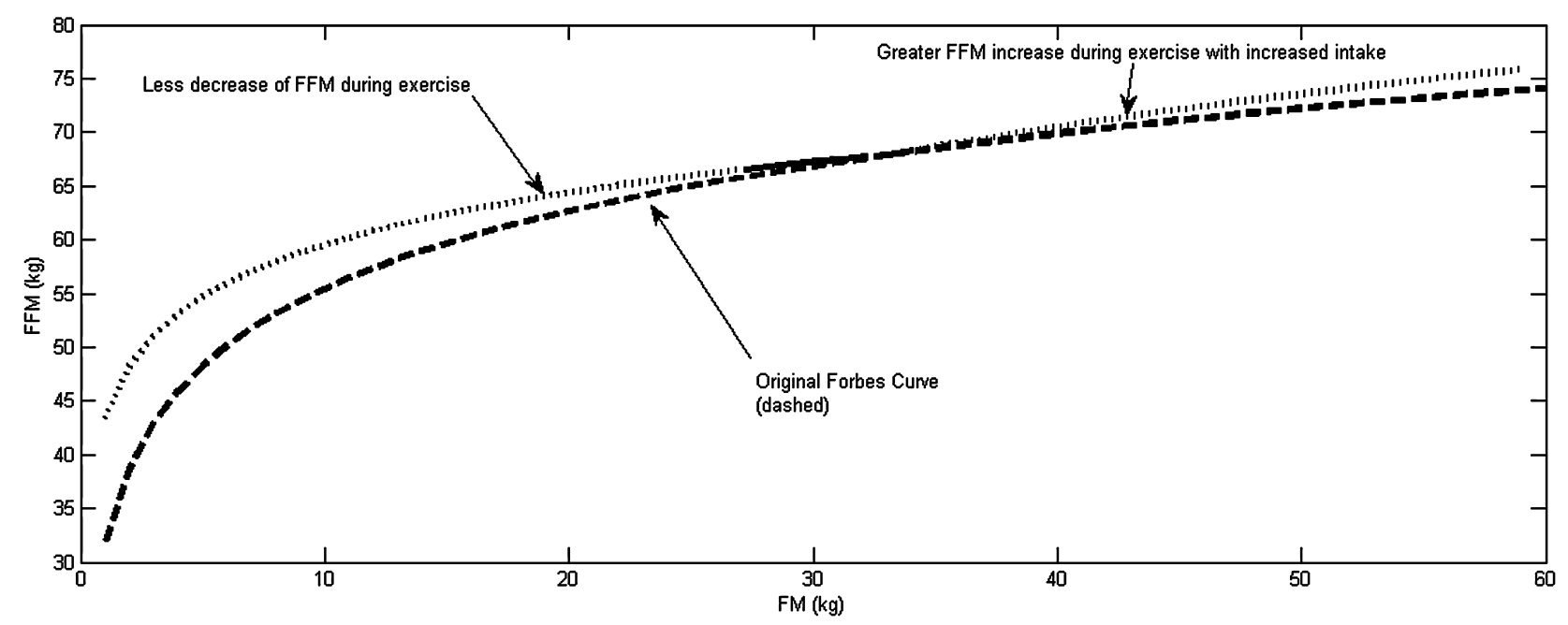

Figure 4 Plot of a proposed modified piecewise Forbes curve (dotted and solid_ modelling body composition during aerobic exercise superimposed over the original Forbes curve [dashed] describing body composition changes during caloric restriction). The top curve models the observation of less fat-free mass (FFM) and more fat mass (FM) during weight loss and assumes greater FFM and less FM during weight gain. Extrapolation of the model beyond available data is indicated by the dotted portion of the top curve.

\section{The modified Forbes curve for aerobic exercise}

We restricted our model development to the Ross study data $(15,16)$ and the INFLAME subjects $(2)$ who increased intake. Applying these two data sets, the parameters $a_{1}$ and $a_{2}$ were determined so that the mean absolute error between final-predicted FFM and model-predicted FFM in Equation 4 is minimized yielding the formula:

$F F M=\left\{\begin{array}{c}7 \ln \left(\frac{F M}{C}\right) \text { if } F M<0, \\ 13.7 \ln \left(\frac{F M}{C}\right) \text { if } F M>0\end{array}\right.$

We validated the newly developed model on the Bouchard study (13) and found the mean absolute error between predicted and observed change in FFM decreased by $89 \%$ in comparison to the classic Forbes curve (Table 2).

The newly developed model predicted a smaller decrease in FFM compared to the Forbes curve. Likewise, if energy intake was increased, the new model predicted a larger increase in FFM than predicted by the Forbes curve. Figure 4 depicts how movement along the newly developed FFM-FM model differs from the traditional Forbes curve.

\section{Discussion}

The present study applied an energy balance analysis to group and individual data from 15 different aerobic exercise studies to analyze why individuals do not lose more weight through prescribed exercise. These analyses and 
observations yield the following conclusions and remaining uncertainties.

\section{What is the energy deficit induced by exercise?}

We have computed the energy imbalance from change in body energy stores generated in 15 different exercise studies. We have shown that the magnitude of energy imbalance generated by 13 of the 15 studies is lower than the typical amount of caloric restriction imposed in the majority of weight loss studies $\left(<500 \mathrm{kcal} \mathrm{d}^{-1}\right)$. We have shown that the achieved energy balance is equal to the prescribed energy expenditures from exercise in a confined study that maintained baseline energy intake and a study that monitored subject energy intake through daily supervision. In the remaining studies, we have shown that the magnitude of negative energy balance is lower than prescribed exercise energy expenditures.

\section{What mechanism explains the discrepancy between actual energy deficit and prescribed energy expenditure of the exercise?}

We investigated whether the small energy imbalance is a result of physiological adaptations or increased dietary intake.

We analyzed whether a possible decrease in RMR may contribute to the low energy imbalance by examining the only study that maintained baseline energy intake for the duration of a supervised exercise intervention in confined subjects. We found mean RMR in this study to be depressed by $7 \%$ beyond weight-related reductions suggesting that there may be an adaptive response if exercise is conducted in combination with an isocaloric diet. The depressed RMR was more pronounced in lean subjects than obese; an observation that may correspond to different dietary responses during exercise observed by Woo et al. $(18,19)$. These results indicate that RMR is reduced when exercise is increased and energy intake is held constant, particularly among individuals with lower levels of FFM and hence lower RMR. This metabolic adaptation reduces the size of the exercise-induced energy deficit and preserves body mass, primarily for leaner individuals.

Unfortunately, the lack of knowledge of how much dietary compensation may have occurred in the remaining exercise studies clouds our understanding of whether there are adaptations to RMR if intake remains unchanged from baseline. To confirm and quantify the degree of adaptation that may be present, more studies that measure RMR alongside DLW and body composition during exercise interventions are critical.

A surprising observation was the repeated finding that almost no change to RMR occurs in response to an exercise intervention with ad libitum energy intake (7). This observation, combined with the results of the Bouchard and Woo studies $(13,18,19)$, leads to a hypothesis that increased dietary intake in response to exercise-induced energy imbalance could be driven by RMR preservation.

Finally, we remark that there does not exist non-exercise activity data collected during an exercise intervention where baseline energy intake was maintained. The evidence that energy imbalance in Bouchard (13) and Ross $(13,15)$ studies closely match prescribed energy expenditure from exercise suggests if it exists, non-exercise activity does not change substantially during an exercise intervention. The increased use of accelerometers in combination with the aforementioned body composition and energy expenditure measurements would provide information to analyze how exercise may influence non-exercise activity, assuming that the accelerometers are sensitive enough to detect these possible changes.

Our analysis of 13 subjects whose energy intake was measured through multiple DLW and body composition measurements (4) revealed that 12 of the subjects $(\sim 92 \%)$ increased dietary intake. We note that this particular intervention involved an intense training program, which prepared previously sedentary subjects to compete in a half marathon. The increased dietary intake observed in the Westerterp subjects (4) is supported by several studies which found similar results at higher exercise doses $(14,42-44)$. It is noteworthy that the discrepancy between achieved energy imbalance and prescribed energy expenditures is larger in magnitude with higher exercise dose $(3,4,14,22)$ (Table 1$)$. This suggests that an important contributor to low energy imbalance when performing a high dose of aerobic exercise is increased dietary intake.

To test whether the degree of compensation is a function of baseline body composition as observed by Woo et al. $(18,19)$, we require additional data containing DLWmeasured EE and simultaneously measured body composition in subjects with a wide range of BMI who are undergoing aerobic exercise. Unfortunately, subjects classified as obese in the only existing exercise study which obtained DLW-measured EE combined with body composition did not complete the study (4). Additional EI data are required to confirm the Woo hypothesis in free-living subjects classified as obese.

\section{What are the expected changes in body composition resulting from an aerobic exercise intervention?}

In two studies where EI was maintained at baseline levels and generated a negative energy balance solely through aerobic exercise, we found that less FFM and more FM is lost than predicted by the Forbes curve. We also found that 
as EI is increased during aerobic training, more gain in FFM and less gain in FM is observed than predicted by the Forbes curve. We have developed and validated a modified piecewise-defined Forbes curve that predicts body composition changes induced by aerobic exercise. Additional data that contain EI, EE and body composition are needed to further advance and validate this model.

We conclude that the small magnitude of weight loss observed from the majority of evaluated exercise intervention studies is primarily due to low doses of prescribed exercise energy expenditures compounded by a concomitant increase in caloric intake; however, exercise has additional beneficial effects that were not considered in the present analysis.

Knowledge of how increased exercise induces physiological changes in the body will improve not only our knowledge of how to treat obesity but stands to improve population-wide health.

\section{Conflict of interest statement}

Timothy Church is a member of the Jenny Craig Medical Advisory Board. Claude Bouchard is a consultant for Weight Watchers International and a member of the Scientific Advisory Board of Pathway Genomics.

\section{Acknowledgements}

Diana M. Thomas is supported by The Herman and Margaret Sokol Institute for Pharmaceutical Life Sciences Fellowship and NIH grants R15 DK090739, U01 DK094418.

Claude Bouchard is partially supported by HL45670 and the John W. Barton Sr. Chair in Genetics and Nutrition.

Timothy Church is supported by NIH R01 HL102166.

Corby K. Martin is supported by NIH grants R01 DK089051，R01 HL102166，P30 DK072476， U01 DK094418 and U01 AG20478.

Leanne M. Redman is supported by NIH grants R00HD060762 and U01 DK094418.

Cris Slentz is supported by NIH grant R01-DK081559.

William E. Kraus is supported by NIH grants R01DK081559 and U01-AG022132.

\section{References}

1. Van Horn LV. Report of the DGAC on the Dietary Guidelines for Americans. 2010. URL http://www.cnpp.usda.gov/DGAs2010DGACReport.htm (accessed February 2012).

2. Church TS, Earnest CP, Thompson AM et al. Exercise without weight loss does not reduce C-reactive protein: the INFLAME study. Med Sci Sports Exerc 2010; 42: 708-716.

3. Slentz CA, Duscha BD, Johnson JL et al. Effects of the amount of exercise on body weight, body composition, and measures of central obesity: STRRIDE - a randomized controlled study. Arch Intern Med 2004; 164: 31-39.
4. Westerterp KR, Meijer GA, Janssen EM, Saris WH, Ten Hoor F. Long-term effect of physical activity on energy balance and body composition. Br J Nutr 1992; 68: 21-30.

5. Donnelly JE, Smith BK. Is exercise effective for weight loss with ad libitum diet? Energy balance, compensation, and gender differences. Exerc Sport Sci Rev 2005; 33: 169-174.

6. Pi-Sunyer FX, Woo R. Effect of exercise on food intake in human subjects. Am J Clin Nutr 1985; 42(5 Suppl.): 983990.

7. Ballor DL, Poehlman ET. A meta-analysis of the effects of exercise and/or dietary restriction on resting metabolic rate. Eur J Appl Physiol Occup Physiol 1995; 71: 535-542.

8. Ross R, Janssen I. Physical activity, total and regional obesity: dose-response considerations. Med Sci Sports Exerc 2001; 33 (6 Suppl.): S521-S527; discussion S528-S529.

9. Speakman JR, Selman C. Physical activity and resting metabolic rate. Proc Nutr Soc 2003; 62: 621-634.

10. Westerterp KR, Meijer GA, Schoffelen P, Janssen EM. Body mass, body composition and sleeping metabolic rate before, during and after aerobic training. Eur J Appl Physiol Occup Physiol 1994; 69: 203-208.

11. Westerterp KR. Pattern and intensity of physical activity. Nature 2001; 410: 539.

12. Westerterp KR. Alterations in energy balance with exercise. Am J Clin Nutr 1998; 68: 970S-974S. Review.

13. Bouchard C, Tremblay A, Després J-P et al. The response to exercise with constant energy intake in identical twins. Obes Res 1994; 2: 400-410.

14. Church TS, Martin CK, Thompson AM, Earnest CP, Mikus CR, Blair SN. Changes in weight, waist circumference and compensatory responses with different doses of exercise among sedentary, overweight postmenopausal women. PLOS ONE 2009; 4: e4515.

15. Ross R, Dagnone D, Jones PJ et al. Reduction in obesity and related comorbid conditions after diet-induced weight loss or exercise-induced weight loss in men. A randomized, controlled trial. Ann Intern Med 2000; 133: 92-103.

16. Ross R, Janssen I, Dawson J et al. Exercise-induced reduction in obesity and insulin resistance in women: a randomized controlled trial. Obes Res 2004; 12: 789-798.

17. Bingham SA, Goldberg GR, Coward WA, Prentice AM, Cummings JH. The effect of exercise and improved physical fitness on basal metabolic rate. Br J Nutr 1989; 61: 155-173.

18. Woo R, Pi-Sunyer FX. Effect of increased physical activity on voluntary intake in lean women. Metabolism 1985; 34: 836841.

19. Woo R, Garrow JS, Pi-Sunyer FX. Voluntary food intake during prolonged exercise in obese women. Am J Clin Nutr 1982; 36: 478-484.

20. Sopko G, Leon AS, Jacobs DR Jr et al. The effects of exercise and weight loss on plasma lipids in young obese men. Metabolism 1985; 34: 227-236.

21. Grediagin A, Cody M, Rupp J, Benardot D, Shern R. Exercise intensity does not effect body composition change in untrained, moderately overfat women. I Am Diet Assoc 1995; 95: 661-665. 22. Goran MI, Poehlman ET. Aerobic training does not enhance total energy expenditure in healthy elderly persons. Am J Physiol 1992; 263(5 Pt 1): E950-E957.

23. Després JP, Pouliot MC, Moorjani S et al. Loss of abdominal fat and metabolic response to exercise training in obese women. Am J Physiol 1991; 261(2 Pt 1): E159-E167.

24. Blaak EE, Westerterp KR, Bar-Or O, Wouters LJ, Saris WH. Total energy expenditure and spontaneous activity in relation to training in obese boys. Am J Clin Nutr 1992; 55: 777-782. 
25. Donnelly JE, Hill JO, Jacobsen DJ et al. Effects of a 16-month randomized controlled exercise trial on body weight and composition in young, overweight men and women: the Midwest Exercise Trial. Arch Intern Med 2003; 163: 1343-1350.

26. Forbes GB. Lean body mass-body fat interrelationships in humans. Nutr Rev 1987; 45: 225-231.

27. Forbes GB. Body fat content influences the body composition response to nutrition and exercise. Ann N Y Acad Sci 2000; 904: 359-365. Review.

28. Forbes GB. Exercise and lean weight: the influence of body weight. Nutr Rev 1992; 50: 157-161. Review.

29. Forbes GB. Exercise and body composition. J Appl Physiol 1991; 70: 994-997.

30. Thomas DM, Schoeller DA, Redman LA, Martin CK, Levine JA, Heymsfield SB. A computational model to determine energy intake during weight loss. Am J Clin Nutr 2010; 92: 13261331.

31. de Jonge L, DeLany JP, Nguyen T et al. Validation study of energy expenditure and intake during calorie restriction using doubly labeled water and changes in body composition. Am J Clin Nutr 2007; 85: 73-79.

32. Pieper C, Redman L, Racette S et al. Development of adherence metrics for caloric restriction interventions. Clin Trials 2011; 8: 155-164.

33. Martin CK, Heilbronn LK, de Jonge L et al. Effect of calorie restriction on resting metabolic rate and spontaneous physical activity. Obesity (Silver Spring) 2007; 15: 2964-2973.

34. Redman LM, Heilbronn LK, Martin CK et al. Metabolic and behavioral compensations in response to caloric restriction: implications for the maintenance of weight loss. PLOS ONE 2009; 4: e4377.
35. Bland JM, Altman DG. Statistical methods for assessing agreement between two methods of clinical measurement. Lancet 1986; 1: 307-310.

36. Hall KD. Body fat and fat-free mass inter-relationships: Forbes's theory revisited. Br J Nutr 2007; 97: 1059-1063.

37. Chow CC, Hall KD. The dynamics of human body weight change. PLoS Comput Biol 2008; 4: e1000045.

38. Hall KD, Sacks G, Chandramohan D et al. Quantification of the effect of energy imbalance on bodyweight. Lancet 2011; 378: $826-837$.

39. Thomas D, Das SK, Levine JA et al. New fat free mass-fat mass model for use in physiological energy balance equations. Nutr Metab (Lond) 2010; 7: 39.

40. Heilbronn LK, de Jonge L, Frisard MI et al. Effect of 6-month calorie restriction on biomarkers of longevity, metabolic adaptation, and oxidative stress in overweight individuals. JAMA 2006; 295: 1539-1548.

41. Schoeller DA. How accurate is self-reported dietary energy intake? Nutr Rev 1990; 48: 373-379.

42. King NA, Horner K, Hills AP et al. Exercise, appetite and weight management: understanding the compensatory responses in eating behaviour and how they contribute to variability in exercise-induced weight loss. Br J Sports Med 2012; 46: 315322.

43. Whybrow S, Hughes DA, Ritz P et al. The effect of an incremental increase in exercise on appetite, eating behaviour and energy balance in lean men and women feeding ad libitum. $\mathrm{Br} J$ Nutr 2008; 100: 1109-1115.

44. Westerterp KR. Physical activity, food intake, and body weight regulation: insights from doubly labeled water studies. Nutr Rev 2010; 68: 148-154. 